\title{
Barriers and facilitators to following the Dietary Guidelines for Americans reported by rural, Northern Plains American-Indian children
}

\author{
Lisa Jahns ${ }^{1, *}$, Leander McDonald ${ }^{2}$, Ann Wadsworth ${ }^{2}$, Charles Morin ${ }^{3}$, Yan Liu ${ }^{4}$ \\ and Theresa Nicklas ${ }^{4}$ \\ 'USDA/ARS Grand Forks Human Nutrition Research Center, 2420 2nd Avenue North, Grand Forks, ND 58203, \\ USA: ${ }^{2}$ Cankdeska Cikana Community College, Spirit Lake Dakota Nation, Fort Totten, ND, USA: ${ }^{3}$ Tate Topa Tribal \\ School, Spirit Lake Dakota Nation, Fort Totten, ND, USA: ${ }^{4}$ USDA/ARS Children's Nutrition Research Center at \\ Baylor College of Medicine, Department of Pediatrics, Houston, Texas, USA
}

Submitted 18 March 2013: Final revision received 15 January 2014: Accepted 5 February 2014: First published online 28 March 2014

\begin{abstract}
Objective: The Dietary Guidelines for Americans (DGA) promote healthy dietary choices for all Americans aged 2 years and older; however, the majority of Americans do not meet recommendations. The goal of the present study was to identify both barriers and facilitators to adherence to DGA recommendations for consumption of five recommended food groups: grains (specifically whole grains), vegetables, fruits, meat/beans and milk (specifically reduced-fat/non-fat), among American-Indian children.

Design: Nominal group technique sessions were conducted to identify and prioritize children's perceived barriers and facilitators to following the DGA, as presented in the 'MyPyramid' consumer education icon. After response generation to a single question about each food group (e.g. "What sorts of things make it harder (or easier) for kids to follow the MyPyramid recommendation for vegetables?'), children individually ranked their top five most salient responses. Ranked responses are presented verbatim.

Setting: A rural Northern Plains American-Indian reservation, USA.

Subjects: Sixty-one self-selected fifth-grade children.

Results: Core barriers for all food groups studied included personal preference (i.e. 'don't like') and environmental (i.e. 'cost too much'; 'store is too far to get them'; 'grandma don't have'). Core facilitators included suggestions, i.e. 'make a garden and plant vegetables'; 'tell your friends to eat healthy'.

Conclusions: Barriers and facilitators are dissimilar for individual food groups, suggesting that dietary interventions should target reduction of barriers and promotion of facilitators specific to individual food groups recommended by the DGA.
\end{abstract}

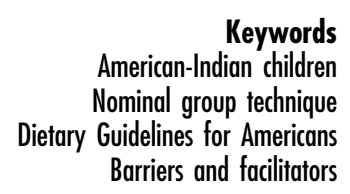

Estimates of obesity among US children aged 6-11 years range from 14 to $24 \%$, depending upon racial/ethnic group, with the highest prevalence observed in minority children $^{(1)}$. Recent estimates of the prevalence of obesity among Northern Plains American-Indian (AI) children is $28 \%{ }^{(2)}$; similar to that reported in other studies ${ }^{(3-5)}$. The number of obese AI children is increasing despite an apparent levelling off among other racial/ethnic groups in the $\mathrm{USA}^{(1,2,6)}$. Obesity is a major risk factor in the development of chronic diseases such as type 2 diabetes (T2DM) and $\mathrm{CVD}^{(7)}$. The prevalence of T2DM in $\mathrm{AI}$ children is one of the highest in the country and continues to increase ${ }^{(8,9)}$. Recent predictions estimate that, without a reduction in obesity, the prevalence of $\mathrm{T} 2 \mathrm{DM}$ in $\mathrm{AI} /$ Alaska Native youth will increase by $129 \%$, from $0 \cdot 56 / 1000$ youths in 2010 to $1 \cdot 28 / 1000$ youths in $2050^{(10)}$, and AI/Alaska Native adults have the highest prevalence of T2DM of all racial/ ethnic groups in the USA ${ }^{(11)}$. Considering that obesity in childhood is likely to persist into adulthood ${ }^{(12)}$, early prevention may be the only way to decrease the significant individual and societal burden of poor health in AI communities ${ }^{(13-16)}$.

Excess energy intake and physical inactivity are risk factors for the development of obesity and obesity-related chronic diseases including $\mathrm{CVD}^{(17-20)}$ and $\mathrm{T}_{2} \mathrm{DM}^{(21)}$. Weight loss, improved diet and physical activity can prevent or delay the onset of obesity, and may even reverse $\mathrm{T}_{2} \mathrm{DM}^{(22)}$. Public health efforts to reduce the burden of 
chronic disease include federal dietary guidance. The Dietary Guidelines for Americans (DGA) are updated every five years and provide food-based recommendations for Americans of all racial and ethnic groups aged 2 years and over. The purpose of both the 2005 and the current 2010 DGA is to promote healthy eating to attain and maintain a healthy body weight and optimal health by offering specific advice to increase consumption of nutrient-dense foods and to decrease high-energy, nutrient-poor foods ${ }^{(23,24)}$. At the time of the present study, the focus was on the 2005 DGA. Key consumer-friendly food groups were highlighted in the US Department of Agriculture's MyPyramid (2005) ${ }^{(25)}$ icon. Since then, the 2010 DGA has released a slightly revised consumer education icon with subtle differences (i.e. the 'milk' group is now the 'dairy' group; 'meat and beans' is now 'protein'), but the food groups are substantially the same. Regardless, the majority of Americans do not comply with the guidelines, particularly minority and low-income groups ${ }^{(26,27)}$. Information about the food intake of AI children is sparse and generally pertains to pre-school children $^{(28)}$, but reports are largely consistent: inadequate intakes of fruit and vegetables ${ }^{(29)}$, whole grains and low-fat dairy $^{(30,31)}$. Dietary interventions may be most effective when tailored to specific race and ethnic groups; therefore we undertook the present study to provide valuable information for designing dietary interventions in this reservation community. The study's objective was to identify barriers and facilitators to consuming recommended food groups from the 2005 DGA: grains, (specifically whole grains), vegetables, fruits, meat/beans and milk (specifically reduced-fat/nonfat), reported by AI children.

\section{Experimental methods}

We conducted the present study as an ancillary to the Healthy Eating and Lifestyle for Total Health (HEALTH) study. HEALTH was a multi-site study involving five Human Nutrition Research Centers and the Delta Obesity Prevention Research Unit supported by the US Department of Agriculture's Agricultural Research Service. The goal of HEALTH was to identify barriers and facilitators to following the DGA in a national sample of fifth-grade children and unrelated caregivers of fifth-grade children. The methods used in the present study were based upon those employed in HEALTH ${ }^{(32)}$.

\section{Participants}

Participants were enrolled members of a Northern Plains tribal community. Participants qualifying for the present study were children in the fifth grade. Recruitment methods included flyers placed in reservation schools and the local Boys and Girls Club, and word of mouth. Each child received a gift card for his/her participation. The study was conducted according to the guidelines laid down in the Declaration of Helsinki and all procedures involving human subjects were approved by tribal resolution and institutional review board. Verbal and written assent was obtained from all children. Data collection occurred from March through December of 2010.

\section{Nominal group technique method}

The nominal group technique (NGT) is a mixed method of data generation and interpretation that combines aspects of qualitative (free generation of responses by individuals) and quantitative (structured multi-step systematic ranking of responses) methodologies ${ }^{(33)}$. The NGT is a consumeroriented formal 'brainstorming' or idea-generating approach effective in helping group members to articulate meaningful disclosures in response to a single, well-articulated question. The highly structured NGT process promotes even rates of participation and equally weights the input from all members, bypassing the effects of power differentials in the group $^{(34)}$. The ordinal data generated by this process are assumed to provide valid and easily interpretable data that reflect the implicit prioritized views held by both individuals and the group ${ }^{(35)}$. As this method has successfully been used with children, adults and other AI tribal communities, it is considered well suited to identify and prioritize salient barriers and facilitators to DGA adherence faced by both children and adults ${ }^{(36-38)}$.

Most individuals have a personal conceptualization of a 'healthy diet (31,39-41). However, the low rates of DGA adherence indicate that most are unaware of the specifics of the DGA. To provide participants in NGT sessions with a cognitive referent for considering barriers and facilitators to DGA adherence, each NGT meeting began with a preamble. The preamble consisted of a brief slide presentation providing both verbal and visual descriptions of the MyPyramid recommendations for the food group addressed in the meeting; for instance, the recommendation to consume 3 cups of reduced-fat/non-fat milk products per day was presented to the milk group participants. NGT meetings were held in schools after classes had ended. Each session was conducted by two facilitators trained by an NGT expert and involved five to eight children. One facilitator acted as a moderator or leader and the other recorded responses on a flip-chart. The NGT method does not require extensive note-taking or audio recording. After viewing the preamble, children were provided a worksheet and asked to work silently to record, as concisely as possible, their responses to a single question: 'What sorts of things make it hard [barriers groups] or easier [facilitators groups] for kids to follow MyPyramid recommendations for eating one of the following: grains; milk; meat \& beans; vegetables; fruits?. Each group was asked only a single question. Next, the children, one at a time, read aloud a single idea from their worksheets until all children had exhausted their list. Each response was recorded verbatim on a flip-chart. A brief clarification process followed in which the facilitator reviewed the written responses with the group to ensure that responses were understood by all. Next, 
children were given five index cards and asked to consider which five responses were most important to them personally, and to record one response on each index card. Still working privately, children were then led through a systematic voting process to prioritize their chosen responses. First, children were asked to choose which of the five responses was most important to them personally, and to write a number five on that card and turn it over. Next, children were asked to identify the response that was least important to them, and to write a number one on the card and turn it over. These steps were repeated with votes two and four; the final card was assigned a vote of three. The ranked votes for the selected responses were summed. In the present paper verbatim NGT responses for barriers and facilitators are presented by food group. The responses children nominated and assigned votes to on their five index cards are presented in descending order by the sum of the votes. Responses receiving no votes are not presented (Tables 1-5) ${ }^{(42)}$. An expert in NGT methodology provided on-site, $2 \mathrm{~d}$ intensive training to all group moderators and recorders. Standardized scripts, protocols, procedures and worksheets were used to ensure standard implementation across all NGT sessions.

\section{Results}

\section{Participant characteristics}

Sixty-one fifth-grade children participated in the five barriers ( $n$ 31) and five facilitators ( $n$ 30) groups. NGT group sizes ranged between five and eight children, evenly split between boys and girls.

\section{Summary of responses to barrier and facilitator questions}

Question: 'What kinds of things make it harder for kids to follow the DGA for...?

Children individually ranked a total of fifty-one barriers. The core barriers reported by children to meeting recommendations for each food group can be grouped into two recurring themes: (i) personal preference (disliking; 39\% of all barriers reported); and (ii) environmental barriers outside the child's control (cost, transportation, none at home; $37 \%$ ). The milk group was the only group that also included physical complaints ('gets me sick'; 'can't drink').

Personal preference. Barriers relating to personal preference for the food groups included the following. Grain (specifically whole grains): 'I don't like oatmeal'; 'I don't like wheat bread'. Vegetables: 'don't like them'; 'gross the taste'. Fruits: 'don't like them much'; 'they are gross'. Meat/ beans: 'don't like a lot of meat'; 'don't like beans'. Milk: 'don't like it'; 'don't like cottage cheese'.

Environmental barriers outside the child's control. Environmental barriers included the following. Grain (specifically whole grains): 'don't have a lot'; 'mom doesn't get the kind of cereal I like'. Vegetables: 'cost too much'; 'store is too far to get them'. Fruits: 'I only get them at school'; 'mom don't get'. Meat/beans: 'mom don't have it cost a lot at store'; 'grandma gets free meat, don't like it'. Milk: 'cost too much'; 'grandma don't have'.

Question: 'What kinds of things make it easier for kids to follow the DGA for...?

Children reported a total of sixty-one facilitators. The core facilitators to meeting recommendations for each food group can be grouped into three recurring themes: (i) suggestions (26\% of all facilitators reported); (ii) environmental (20\%); and (iii) personal preference (13\%).

Suggestions. Suggestions for following the DGA included the following. Meat/beans: 'you can make it how you want'. However, most suggestions were for the vegetable group: 'put vegetables out for lunch'; 'make a garden and plant vegetables'; 'try the ones you don't like'.

Environmental. Facilitators related to the food environment included the following. Grain (specifically whole grains): 'my mom buys noodles'. Fruits: 'I get them at school'. Meat/beans: 'lower prices on the food so people can buy them'. Milk: 'I walk to the store for yoghurt'.

Personal preference. Few children ranked facilitator responses relating to personal preference for the food

Table 1 Barriers and facilitators to meeting fruit group recommendations reported by American-Indian children (responses ranked by vote) from a rural Northern Plains reservation, March-December 2010

\begin{tabular}{|c|c|c|c|c|c|}
\hline \multicolumn{3}{|c|}{ Barriers } & \multicolumn{3}{|c|}{ Facilitators } \\
\hline Responses & Voting & Sum score & Responses & Voting & Sum score \\
\hline Don't like them much & $2,4,4,3,5$ & 18 & Vitamin C & $5,3,1,4$ & 13 \\
\hline Mom don't get & $4,2,1,2,1$ & 10 & I like fruit & $2,5,1,4$ & 12 \\
\hline They are gross & $3,5,3,3,1$ & 15 & I like fruit snacks & $2,3,2,1$ & 8 \\
\hline There is only a little bit at home & $2,1,4,3$ & 10 & Fruit is good & $4,3,3$ & 10 \\
\hline I only get them at school & $1,5,5$ & 11 & Mommy gets them at the star & 5,5 & 10 \\
\hline Apples are hard to eat & 2,4 & 6 & I get them at school & 1,5 & 6 \\
\hline \multirow[t]{4}{*}{ The apples get mushie } & 5 & 5 & Can't live w/o fruit & 1,3 & 4 \\
\hline & & & Fruit bars are good & 2,2 & 4 \\
\hline & & & Apple make a lot of stuff & 4 & 4 \\
\hline & & & Peaches I eat & 4 & 4 \\
\hline
\end{tabular}


Table 2 Barriers and facilitators to meeting vegetable group recommendations reported by American-Indian children (responses ranked by vote) from a rural Northern Plains reservation, March-December 2010

\begin{tabular}{|c|c|c|c|c|c|}
\hline \multicolumn{3}{|c|}{ Barriers } & \multicolumn{3}{|l|}{ Facilitators } \\
\hline Responses & Voting & Sum score & Responses & Voting & Sum score \\
\hline Don't like them & $5,3,5,5,3,1,4$ & 26 & Put vegetables out for lunch & $4,4,3,5$ & 16 \\
\hline Mom don't buy them & $2,5,1,3,1,4,1$ & 17 & Make a garden and plant vegetables & $5,4,4$ & 13 \\
\hline Gross the taste & $3,4,2,1,2$ & 12 & Try the ones you don't like & $3,4,5$ & 12 \\
\hline Don't like the way they taste & $1,3,1,5,3$ & 13 & Tell your friends to eat healthy & 1,5 & 6 \\
\hline No time & $4,4,4,4$ & 16 & Eat more each day & 2,3 & 5 \\
\hline They smell funny & $2,5,2$ & 9 & 12 baby carrots & 5 & 5 \\
\hline Look funny & 4,5 & 9 & Eat the same or different vegetables & 3 & 3 \\
\hline Cost too much & 3,2 & 5 & Eat vegetables in salads & 3 & 3 \\
\hline Grandma don't cook them & 3,2 & 5 & Put them on each plate & 2 & 2 \\
\hline School don't have the kind I like & 1,2 & 3 & 8 ounces of vegetable juice & 2 & 2 \\
\hline \multirow[t]{6}{*}{ Store is too far to get them } & 5 & 5 & Eat 1 ear of corn each day & 2 & 2 \\
\hline & & & Eat from the starch group & 2 & 2 \\
\hline & & & Tell your friends to eat them & 1 & 1 \\
\hline & & & Tell you friends to try them & 1 & 1 \\
\hline & & & Tell your friends to eat them everyday & 1 & 1 \\
\hline & & & Try to mix vegetables together to try different ones & 1 & 1 \\
\hline
\end{tabular}

Table 3 Barriers and facilitators to meeting grain group recommendations reported by American-Indian children (responses ranked by vote) from a rural Northern Plains reservation, March-December 2010

\begin{tabular}{|c|c|c|c|c|c|}
\hline \multicolumn{3}{|l|}{ Barriers } & \multicolumn{3}{|c|}{ Facilitators } \\
\hline Responses & Voting & Sum score & Responses & Voting & Sum score \\
\hline I don't like oatmeal & $4,4,4,3,3$ & 18 & I like cereal & $3,4,5,5,5,2,1,1$ & 26 \\
\hline I don't like how they look & $2,2,2,5,2$ & 13 & Good for you & $4,3,3,2,2,2,1$ & 17 \\
\hline Don't have a lot & $3,1,5$ & 9 & Mom makes rice & $5,4,2$ & 11 \\
\hline Mom doesn't get the kind of cereal I like & $1,3,1$ & 5 & My mom buys noodles & $2,3,4$ & 9 \\
\hline Rice smells funny & 5,4 & 9 & It's good - eat! & $1,1,4$ & 6 \\
\hline I don't like wheat bread & 5,1 & 6 & Like the way it taste & 4,3 & 7 \\
\hline I like butter with my noodles & 1,2 & 3 & They look good & 3,2 & 5 \\
\hline I just like corn pops & 5 & 5 & Grandma cooks & 1,3 & 4 \\
\hline Noodles get mushy & 4 & 4 & I eat cereal & 5 & 5 \\
\hline Mom don't make rice & 3 & 3 & & & \\
\hline
\end{tabular}

groups; the only taste responses were the following. Grain (specifically whole grains): 'I like cereal'. Fruits: 'I like fruit'. Meat/beans: 'taste good'.

\section{Discussion}

In the present study, fifth-grade children reported barriers and facilitators to following the 2005 DGA recommendations for five food groups to encourage in the diet. One-third of ranked responses in barrier NGT groups reflected environmental factors, predominantly to following recommendations for vegetables, milk and meat/beans consumption. One-third of the ranked responses in facilitator groups, in particular the vegetable group, consisted of advice to kids for increasing consumption. Barriers and facilitators were dissimilar for individual food groups, suggesting that interventions should target reduction of barriers and promotion of facilitators for individual food groups recommended by the DGA. For instance, barriers to milk consumption were different from those for vegetables or fruits.
Results from the HEALTH study identified several key barriers to milk consumption reported by a national sample of fifth-grade children, including lactose intolerance, taste and lack of availability in the home. In the present study, children identified similar barriers to milk consumption, but also reported cost as one of the top ten barriers. Recently, the strength of the scientific evidence emphasizes health benefits of whole grain consumption, but consumers still struggle with disliking whole grains, knowledge of what a constitutes a whole grain food, how to cook and perceived cost ${ }^{(43)}$. A recent study of correlates with whole grain intake in children reported that availability in the home was more strongly associated with intake than preference ${ }^{(44)}$. However, AI children in the present study reported disliking grains (specifically whole grains) such as rice and wheat bread as the primary reason for not meeting the grain (specifically whole grains) recommendations. Facilitators however were mixed including home access, liking the way grains (specifically whole grains) look and taste, and being good for you. Continued research to improve consumer acceptance 
Table 4 Barriers and facilitators to meeting meat/beans group recommendations reported by American-Indian children (responses ranked by vote) from a rural Northern Plains reservation, March-December 2010

\begin{tabular}{|c|c|c|c|c|c|}
\hline \multicolumn{3}{|l|}{ Barriers } & \multicolumn{3}{|l|}{ Facilitators } \\
\hline Responses & Voting & Sum score & Responses & Voting & Sum score \\
\hline $\begin{array}{l}\text { Mom don't have it cost a lot at store } \\
\text { I eat only hamburger } \\
\text { Don't like a lot of meats } \\
\text { Don't like beans } \\
\text { Meat makes me fat } \\
\text { Like chicken nuggets } \\
\text { Grandma doesn't buy } \\
\text { Eat at McDonalds } \\
\text { Don't like peanut butter } \\
\text { School don't have the kind I like } \\
\text { Grandma gets free meat, don't like } \\
\text { Don't like to eat too much } \\
\text { Most meat has a lot of fat on it }\end{array}$ & $\begin{array}{c}4,5,5,1 \\
1,1,1,5 \\
3,5,2 \\
3,2,4 \\
2,4,5 \\
2,1,2 \\
5,1 \\
4,3 \\
4 \\
3 \\
3 \\
3 \\
2\end{array}$ & $\begin{array}{r}19 \\
8 \\
10 \\
9 \\
11 \\
5 \\
6 \\
7 \\
4 \\
3 \\
3 \\
3 \\
2\end{array}$ & $\begin{array}{l}\text { Low in fat } \\
\text { To get protein in your body } \\
\text { You can mix it with other things } \\
\text { You can make it how you want } \\
\text { Stores are close } \\
\text { Lots to choose from } \\
\text { Lower prices on the food so people can buy them } \\
\text { Taste good } \\
\text { Dad likes to cook them } \\
\text { Good for you } \\
\text { Everyone eats it } \\
\text { Food is good for your body } \\
\text { Ex to make } \\
\text { Buy them all the time } \\
\text { The store has it }\end{array}$ & $\begin{array}{l}5,5,5,5,5 \\
3,4,3,4,4 \\
1,3,1,4 \\
3,4,4 \\
4,2,2 \\
1,3,3 \\
3,5 \\
2,2 \\
1,2 \\
5 \\
2 \\
2 \\
1 \\
1 \\
1\end{array}$ & $\begin{array}{r}25 \\
18 \\
11 \\
9 \\
8 \\
8 \\
7 \\
5 \\
4 \\
3 \\
2 \\
2 \\
1 \\
1 \\
1\end{array}$ \\
\hline
\end{tabular}

Table 5 Barriers and facilitators to meeting milk group recommendations reported by American-Indian children (responses ranked by vote) from a rural Northern Plains reservation, March-December 2010

\begin{tabular}{|c|c|c|c|c|c|}
\hline \multicolumn{3}{|c|}{ Barriers } & \multicolumn{3}{|l|}{ Facilitators } \\
\hline Responses & Voting & Sum score & Responses & Voting & Sum score \\
\hline Gets me sick & $3,5,3,2,1,4,3,1$ & 22 & I drink milk & $2,5,5,1,2$ & 15 \\
\hline Can't drink & $3,1,3,4,4,5$ & 20 & I walk to the store for yoghurt & $5,4,5,2$ & 16 \\
\hline Don't like it & $2,1,4,5$ & 12 & I have string cheese & $4,4,4,4$ & 16 \\
\hline We don't have them & $2,5,2$ & 9 & Cow on the farm helps us have milk & $4,1,1,1$ & 7 \\
\hline Don't like cottage cheese & $2,4,2$ & 8 & I have milk with ice cream & $2,1,1,2$ & 6 \\
\hline Cost to much & 3,1 & 4 & I have milk for breakfast & $5,3,3$ & 11 \\
\hline Cheese & 1,3 & 4 & I can walk to the store to get some milk & 5,5 & 10 \\
\hline Only drink at supper time & 5 & 5 & I have yoghurt for breakfast & 2,4 & 6 \\
\hline Grandma don't have & 3 & 3 & Chilli w/cheese & 3 & 3 \\
\hline \multirow{6}{*}{ Yoghurt } & 3 & 3 & I have milk at home & 3 & 3 \\
\hline & & & I have yoghurt all the time & 3 & 3 \\
\hline & & & Cottage cheese with peaches & 3 & 3 \\
\hline & & & I have cheese on my Indian taco with sour cream & 3 & 3 \\
\hline & & & Cheese with tacos & 2 & 2 \\
\hline & & & Cottage for lunch at school & 1 & 1 \\
\hline
\end{tabular}

and adoption of whole grain foods is warranted; particularly among children. As recently reviewed, a number of studies have identified barriers and facilitators to vegetable and fruit consumption in children ${ }^{(45)}$; but none in $\mathrm{AI}$ children. Consistent with previous studies, the top barriers to vegetable consumption were dislike; but cost and access (home, school and store) were also ranked high in our responses. To our knowledge, no studies of determinants of healthy eating have also included the meat/ beans group.

Children living in rural areas are $25 \%$ more likely to be overweight or obese than children living in non-rural areas $^{(46)}$ and have poorer diets than reported in the general population $^{(30)}$. Rural residency alone presents a unique set of barriers to healthy eating including high cost, long commutes and poor quality of fresh foods ${ }^{(41)}$. Formative research for Pathways, a large, multi-site obesity prevention initiative in tribal communities, found that caregivers of schoolchildren reported driving considerable distances to shop at grocery or discount stores to acquire food for the family, due to reported poor availability of fresh fruits, vegetables and low-fat dairy at local reservation stores ${ }^{(31)}$. In a recent study conducted in another rural Northern Plains reservation, $40 \%$ of households reported low food security ${ }^{(47)}$, reinforcing the need for environmental interventions to increase affordable nutrient-rich food choices on or near the reservation as well as individual-level dietary interventions. In the present study, children's reporting of cost and no availability in local stores as barriers indicates that children may be well aware of the difficulties their parents face in shopping for the family.

Obesity prevention efforts in AI communities have had limited success, despite careful attention to study design and community involvement ${ }^{(31,48,49)}$. AI tribal communities are heterogeneous; each faces unique geographic, cultural and economic situations. While research with 
AI communities has some generalizable import for all reservations, information is obviously most relevant to the community where the information was generated. Successful efforts to improve eating and physical activity behaviours may best be achieved by working hand-inhand with each tribal community. On the reservation where the present study was conducted, chronic disease risk reduction is a priority of the tribe, but currently other, more basic needs such as substance abuse, lack of safe housing and physical and social recreation opportunities, employment and emergency response have been identified as most pressing ${ }^{(50)}$.

Difficulties in completing this type of face-to-face study on the reservation can be marked, even with monetary incentives and snack provision ${ }^{(51)}$. The amount of coordination required to complete this effort was tremendous due to winter storms, flooding, school schedules, district and regional tournaments, transportation and frontier rurality. The above-mentioned barriers may also be significant barriers to the implementation and sustainability of local interventions.

Nevertheless, the results of the study will provide the tribe with means to specifically target interventions to improve recommended food group consumption. The present study is the first one to identify barriers and facilitators to healthy eating in AI children in the context of the DGA. To our knowledge, the only study of consumption of food groups recommended by the DGA by AI children was conducted with children of pre-school age ${ }^{(28)}$. Future studies are warranted to link barriers and facilitators to reported intake in older children, who may have more autonomy in food choices.

Limitations of the study include having only one group for each barrier and facilitator question. However, many qualitative studies report results from single groups. In addition, the NGT process minimizes the 'group dynamic' situation that can occur in less-structured groups. These results are not directly applicable to the general US population of fifth-graders, but their value lies precisely in that they reflect the barriers and facilitators to DGA adherence specific to AI children in this community.

While children reported not liking recommended foods, i.e. vegetables, nearly as many ranked responses referred to environmental factors specifically as a major barrier to consumption (39\% v. $37 \%$ ). Improving the acceptance of recommended food groups in children is difficult unless the foods are within the child's reach. Efforts to reduce barriers to consumption of recommended food groups should include increased availability and accessibility of affordable food options such as reduced-fat/non-fat dairy, vegetables and fruits in schools, grocery stores and commodity distribution sites as a critical intermediate step to behaviour change. Promotion of facilitators include educational programmes specific to the community, the children and their families and should emphasize food-based recommendations, guidance on preparation of unfamiliar foods, and food tastings to expose children to low-fat dairy, meat/ beans, vegetables, fruits and whole grains.

\section{Conclusions}

The findings of the present study resulted in two key accomplishments: first, identifying children's self-reported barriers and facilitators to following the DGA recommendations; and second, increasing the intervention capacity of this tribal community. To our knowledge, the present study is the first to provide a child's view of the problems, and opportunities, around complying with federal dietary guidance on a rural reservation. These results may benefit the community, and provide valuable information to support tribal community efforts to improve the health of children through the application, adoption and adherence to recommendations by the 2005 and 2010 DGA.

\section{Acknowledgements}

Acknowledgements: The authors would like to gratefully acknowledge Bonita Hoverson, Bonnie Thompson, Doreen Rolshoven, Doris Zidon, Mary Jo Peltier and Rebecca Stadstad at the Grand Forks Human Nutrition Research Center for their assistance in data collection; Angi Scheett for editorial assistance; and the children and caregivers who gave of their time and expertise to participate in the study. Financial support: This work was supported the US Department of Agriculture (USDA), Agricultural Research Service (grant number USDA 545051000-049-00D). The contents of this publication do not necessarily reflect the views or policies of the USDA or the Agricultural Research Service, nor does mention of trade names, commercial products or organizations imply endorsement from the US government. The USDA had no role in the design, analysis or writing of this article. Conflict of interest: None. Authorship: T.N. designed the parent HEALTH study, participated in data management and interpretation, and made substantial comments and revisions on the manuscript. L.J. and L.M. planned the study, oversaw training and project management and implementation, and obtained tribal and human subject approvals. L.M., C.M. and A.W. oversaw data collection. Y.L. analysed the data. L.J. drafted the manuscript and L.M., A.W., C.M., Y.L. and T.N. participated in data interpretation and reviewing, finalizing and approving the manuscript. Ethics of buman subject participation: The study was reviewed and approved by the Institutional Review Board of the University of North Dakota.

\section{References}

1. Ogden CL, Carroll MD, Kit BK et al. (2012) Prevalence of obesity and trends in body mass index among US children and adolescents, 1999-2010. JAMA 307, 483-490. 
2. Zephier E, Himes JH, Story M et al. (2006) Increasing prevalences of overweight and obesity in Northern Plains American Indian children. Arch Pediatr Adolesc Med 160 , 34-39.

3. Janitz AE, Moore WE, Stephens AL et al. (2012) Weight status of American Indian and white elementary school students living in the same rural environment, Oklahoma, 2005-2009. Prev Chronic Dis 9, E78.

4. Eichner JE, Moore WE, Perveen G et al. (2008) Overweight and obesity in an ethnically diverse rural school district: the Healthy Kids Project. Obesity (Silver Spring) 16, 501-504.

5. Caballero B, Himes JH, Lohman T et al. (2003) Body composition and overweight prevalence in 1704 schoolchildren from 7 American Indian communities. Am J Clin Nutr 78, 308-312.

6. Madsen KA, Weedn AE \& Crawford PB (2010) Disparities in peaks, plateaus, and declines in prevalence of high BMI among adolescents. Pediatrics 126, 434-442.

7. Isomaa B, Almgren P, Tuomi T et al. (2001) Cardiovascular morbidity and mortality associated with the metabolic syndrome. Diabetes Care 24, 683-689.

8. Dabelea D, Hanson RL, Bennett PH et al. (1998) Increasing prevalence of type II diabetes in American Indian children. Diabetologia 41, 904-910.

9. Fagot-Campagna A, Burrows NR \& Williamson DF (1999) The public health epidemiology of type 2 diabetes in children and adolescents: a case study of American Indian adolescents in the Southwestern United States. Clin Chim Acta 286, 81-95.

10. Imperatore G, Boyle JP, Thompson TJ et al. (2012) Projections of type 1 and type 2 diabetes burden in the US population aged $<20$ years through 2050: dynamic modeling of incidence, mortality, and population growth. Diabetes Care 35, 2515-2520.

11. Barnes PM, Adams PF \& Powell-Griner E (2010) Health Characteristics of the American Indian or Alaska Native Adult Population: United States, 2004-2008. National Health Statistics Reports no. 20. Hyattsville, MD: National Center for Health Statistics; available at http://www.cdc. gov/nchs/data/nhsr/nhsr020.pdf

12. Singh AS, Mulder C, Twisk JW et al. (2008) Tracking of childhood overweight into adulthood: a systematic review of the literature. Obes Rev 9, 474-488.

13. O'Connell JM, Wilson C, Manson SM et al. (2012) The costs of treating American Indian adults with diabetes within the Indian Health Service. Am J Public Health 102, 301-308.

14. Story M, Evans M, Fabsitz RR et al. (1999) The epidemic of obesity in American Indian communities and the need for childhood obesity-prevention programs. Am J Clin Nutr 69 , Suppl. 4, 747S-754S.

15. Holm JE, Vogeltanz-Holm N, Poltavski D et al. (2010) Assessing health status, behavioral risks, and health disparities in American Indians living on the Northern Plains of the US. Public Health Rep 125, 68-78.

16. O'Connell J, Yi R, Wilson C et al. (2010) Racial disparities in health status: a comparison of the morbidity among American Indian and US adults with diabetes. Diabetes Care 33, $1463-1470$.

17. Xu J, Eilat-Adar S, Loria C et al. (2006) Dietary fat intake and risk of coronary heart disease: the Strong Heart Study. $A m \mathrm{~J}$ Clin Nutr 84, 894-902.

18. Ness AR \& Powles JW (1997) Fruit and vegetables, and cardiovascular disease: a review. Int J Epidemiol 26, 1-13.

19. Dehghan M, Mente A, Teo KK et al. (2012) Relationship between healthy diet and risk of cardiovascular disease among patients on drug therapies for secondary prevention: a prospective cohort study of 31546 high-risk individuals from 40 countries. Circulation 126, 2705-2712.
20. Fogelholm M (2010) Physical activity, fitness and fatness: relations to mortality, morbidity and disease risk factors. A systematic review. Obes Rev 11, 202-221.

21. Costacou T \& Mayer-Davis EJ (2003) Nutrition and prevention of type 2 diabetes. Annu Rev Nutr 23, 147-170.

22. Gregg EW, Chen H, Wagenknecht LE et al. (2012) Association of an intensive lifestyle intervention with remission of type 2 diabetes. JAMA 308, 2489-2496.

23. Department of Health and Human Services \& US Department of Agriculture (2005) Dietary Guidelines for Americans. Washington, DC: US Government Printing Office; available at http://www.health.gov/dietaryguidelines/dga2005/

24. US Department of Agriculture (2010) Report of the Dietary Guidelines Advisory Committee on the Dietary Guidelines for Americans, 2010. http://www.cnpp.usda.gov/DGAs2010DGACReport.htm (accessed December 2012).

25. US Department of Health and Human Services \& US Department of Agriculture (2005) Dietary Guidelines for Americans. Washington, DC: US Government Printing Office; available at http://www.health.gov/dietaryguidelines/ dga2005/toolkit/

26. Krebs-Smith SM, Guenther PM, Subar AF et al. (2010) Americans do not meet federal dietary recommendations. J Nutr 140, 1832-1838.

27. Kirkpatrick SI, Dodd KW, Reedy J et al. (2012) Income and race/ethnicity are associated with adherence to food-based dietary guidance among US adults and children. J Acad Nutr Diet 112, 624-635.

28. LaRowe TL, Adams AK, Jobe JB et al. (2010) Dietary intakes and physical activity among preschool-aged children living in rural American Indian communities before a familybased healthy lifestyle intervention. J Am Diet Assoc 110, 1049-1057.

29. Ricci CL, Brown BD, Noonan C et al. (2012) Parental influence on obesity in Northern Plains American Indian youth. Fam Community Health 35, 68-75.

30. Stroehla BC, Malcoe LH \& Velie EM (2005) Dietary sources of nutrients among rural Native American and white children. I Am Diet Assoc 105, 1908-1916.

31. Gittelsohn J, Toporoff EG, Story M et al. (2000) Food perceptions and dietary behavior of American-Indian children, their caregivers, and educators: formative assessment findings from Pathways. J Nutr Educ 31, 2-13.

32. Nicklas TA, Jahns L, Bogle ML et al. (2013) Barriers and facilitators for consumer adherence to the Dietary Guidelines for Americans: the HEALTH study. I Acad Nutr Diet 113, 1317-1331.

33. Van de Ven A \& Delbecq A (1972) The nominal group as a research instrument for exploratory health studies. $A m ~ J$ Public Health 62, 337-342.

34. Asmus CL \& James K (2005) Nominal group technique, social loafing, and group creative project quality. Creativity Res J 17, 349-354.

35. Miller D, Shewchuk R, Elliot TR et al. (2000) Nominal group technique: a process for identifying diabetes self-care issues among patients and caregivers. Diabetes Educ 26, 305-314.

36. Vella K, Goldfrad C, Rowan K et al. (2000) Use of consensus development to establish national research priorities in critical care. BMJ 320, 976-980.

37. MacPhail A (2001) Nominal group technique: a useful method for working with young people. Br Educ Res J 27, 161-170.

38. Jefferson WK, Zunker C, Feucht JC et al. (2010) Use of the nominal group technique (NGT) to understand the perceptions of the healthiness of foods associated with African Americans. Eval Program Plann 33, 343-348.

39. Croll JK, Neumark-Sztainer D \& Story M (2001) Healthy eating: what does it mean to adolescents? J Nutr Educ 33, 193-198. 
40. Bisogni CA, Jastran M, Seligson M et al. (2012) How people interpret healthy eating: contributions of qualitative research. J Nutr Educ Behav 44, 282-301.

41. Yousefian A, Leighton A, Fox K et al. (2011) Understanding the rural food environment - perspectives of low-income parents. Rural Remote Health 11, 1631.

42. Elliott TR \& Shewchuk RM (2002) Using the nominal group technique to identify the problems experienced by persons living with severe physical disabilities. J Clin Psychol Med Settings 9, 65-76.

43. McMackin E, Dean M, Woodside JV et al. (2013) Whole grains and health: attitudes to whole grains against a prevailing background of increased marketing and promotion. Public Health Nutr 16, 743-751.

44. Rosen R, Burgess-Champoux T, Marquart L et al. (2012) Associations between whole-grain intake, psychosocial variables, and home availability among elementary school children. J Nutr Educ Behav 44, 628-633.

45. Krølner R, Rasmussen M, Brug J et al. (2011) Determinants of fruit and vegetable consumption among children and adolescents: a review of the literature. Part II: qualitative studies. Int J Behav Nutr Phys Act 8, 112.
46. Lutfiyya MN, Lipsky MS, Wisdom-Behounek J et al. (2007) Is rural residency a risk factor for overweight and obesity for US children? Obesity (Silver Spring) 15, 2348-2356.

47. Brown B, Noonan C \& Nord M (2007) Prevalence of food insecurity and health-associated outcomes and food characteristics of Northern Plains Indian households. J Hunger Environ Nutr 1, 37-53.

48. Caballero B, Clay T, Davis SM et al. (2003) Pathways: a school-based, randomized controlled trial for the prevention of obesity in American Indian schoolchildren. Am J Clin Nutr 78, 1030-1038.

49. Gittelsohn J \& Rowan M (2011) Preventing diabetes and obesity in American Indian communities: the potential of environmental interventions. Am J Clin Nutr 93, issue 5, 1179S-1183S

50. McDonald LR (2007) Spirit Lake Tribe Strategic Plan 2008-2013. Fort Totten, ND: Spirit Lake Planning Department, Spirit Lake Dakota Nation.

51. Gittelsohn J, Evans M, Helitzer D et al. (1998) Formative research in a school-based obesity prevention program for Native American school children (Pathways). Health Educ Res 13, 251-265. 